\title{
Effects of Ethanol and Methanol on Lipid Metabolism in Bacillus subtilis
}

\author{
By DANIEL RIGOMIER,* JEAN-PIERRE BOHIN AND \\ BERNARD LUBOCHINSKY \\ Laboratoire de Biochimie Cellulaire C.N.R.S., L.A. 290-Biomembranes, \\ U.E.R. Sciences, Avenue du Recteur Pineau, 86022 Poitiers Cedex, France
}

(Received 29 November 1979; revised 25 January 1980)

\begin{abstract}
In Bacillus subtilis, the fatty acid moiety of the phospholipids was affected differently during growth in the presence of $1.1 \mathrm{M}$-methanol or $0.7 \mathrm{M}$-ethanol, though at these concentrations methanol and ethanol had the same effects on growth rate and completely inhibited sporulation. Synthesis of phosphatidylglycerol was also strongly inhibited and the amount of total cell phospholipids was reduced by $50 \%$ by both alcohols. The composition of fatty acids, especially the relative concentration of 12-methyltetradecanoic acid, was modified only by ethanol; in bacteria grown in the presence of methanol, changes in fatty acid composition were negligible. In non-sporulating mutants, synthesis of phosphatidylglycerol was much less affected than in the wild-type and synthesis of phosphatidylethanolamine was increased. In these strains, fatty acid composition was also modified by ethanol but unaffected by methanol.
\end{abstract}

\section{INTRODUCTION}

When alcohols of various chain lengths are added to growing cultures of Bacillus subtilis, the growth rate is decreased (Bohin et al., 1976). This effect is more pronounced with alcohols of longer chain length and at higher temperatures. Alcohol concentrations which reduce the growth rate to half its maximum value, without changing the final yield, completely inhibit sporulation. Post-exponential phase events, such as seryl-protease and esterase excretion, normally observed during sporulation, are also affected. Since alcohols disturb the structure of biological membranes (Patterson et al., 1972; Lenaz et al., 1976), changes in many functions dependent on membrane integrity might be expected.

The fact that perturbation of phospholipid metabolism depends on the nature of the alcohol used illustrates the usefulness of alcohols for analysing membrane interactions (Harold, 1970). If alcohols act by decreasing membrane viscosity as a consequence of their solubilization in the lipid phase, bacteria should adapt their lipid composition as they do when grown at different temperatures. Fatty acid composition is adjusted in response to growth temperature (Marr \& Ingraham, 1962); mechanisms for this regulation have been documented in Escherichia coli (Okuyama et al., 1977; Sinensky, 1974) and in Bacillus megaterium (Fujii \& Fulco, 1977). But a modification in the distribution of polar headgroups could also change lipid-lipid interactions as well as lipid-protein and proteinprotein interactions (Michaelson et al., 1974; Vaughan \& Keough, 1974).

The phospholipid composition of Bacillus cereus was effectively modified when cells were incubated with $0.2 \mathrm{M}$-ethanol or $0.08 \mathrm{M}$-propanol (Kates et al., 1962); in bacteria grown overnight under these conditions, the amount of total phospholipids and that of the $\mathrm{C}_{15}$ branched fatty acid increased slightly. 
In lipids from $E$. coli grown in medium to which ethanol was added, an unexpected increase in vaccenic acid content (Ingram, 1977a) was observed, while the total amount of phospholipids was not changed except at ethanol concentrations higher than $0.2 \mathrm{M}$. The ratio of the two main lipids, phosphatidylethanolamine and phosphatidylglycerol, was unchanged.

These results on the effects of short-chain alcohols cannot be generalized to all bacterial species. While looking for a mechanism of regulation of phospholipid synthesis in Bacillus subtilis, we have compared the effects of ethanol and methanol on lipid metabolism in sporulating and asporogenous strains. In cells grown with ethanol the relative amount of branched fatty acids in phospholipids was markedly decreased and synthesis of phosphatidylglycerol was inhibited. Methanol, while also inhibiting phosphatidylglycerol synthesis, had no effect on the fatty acid composition.

\section{METHODS}

Strains and culture. The Marburg strain of Bacillus subtilis SMY, and spo0A asporogenous mutants derived from it, were from P. Schaeffer (Michel et al., 1968). Cells were grown in conditioned nutrient broth (Rigomier et al., 1974) at $37^{\circ} \mathrm{C}$ with vigorous aeration. Growth was measured turbidimetrically at $600 \mathrm{~nm}$ using a Jobin-Yvon spectrophotometer (Jobin et Yvon, Longjumeau, France).

Extraction and identification of phospholipids. Perchloric acid $(0.5 \mathrm{M})$ was added directly to exponentially growing cells. After centrifugation the pellet was washed with $0.5 \mathrm{M}$-perchloric acid $\left(50 \mathrm{~mm}-\mathrm{NaH}_{2} \mathrm{PO}_{4}\right.$ was added when phospholipids were labelled with $\left.{ }^{32} \mathrm{P}\right]$ phosphate), then extracted with a methanol/chloroform/ water mixture as described by Bligh \& Dyer (1959). The final chloroform solution was used for the estimation of phospholipid content and for fatty acid analysis. The lipid components have been identified previously (Rigomier \& Lubochinsky, 1974).

Fatty acid analysis. The chloroform extract was concentrated under nitrogen and transesterified by heating with acidified anhydrous methanol (Saito \& McElhaney, 1977) for $4 \mathrm{~h}$ at $75^{\circ} \mathrm{C}$. Methyl esters extracted into hexane were analysed by isothermal gas chromatography at $190^{\circ} \mathrm{C}$ on a Hewlett-Packard 7620A chromatograph equipped with a flame ionization detector. Two different columns were used: one packed with $20 \%$ diethylene glycol succinate-coated Chromosorb W, the other with $10 \%$ of the non-pclar methyl silicone $\mathrm{OV}_{1}$ on Chromosorb Q (Analabs). Fatty acid esters were identified by their relative retention times on both columns and after co-chromatography with known standards (Analabs).

The relative composition of the whole extract was calculated using the relation: \% $S_{n}=\left[\left(h_{n} \times t_{n}\right) /\right.$ $\Sigma(h \times t)] \times 100$, where $h$ is the height of the peak and $t$ the retention time for the fatty acid $\mathbf{S}$ with $\mathrm{n}$ carbons.

\section{RESULTS}

\section{Effects of methanol and ethanol on growth}

When methanol or ethanol was added to exponentially growing bacteria in conditioned nutrient broth, their growth rate was decreased. In this medium, the inhibition was biphasic (Fig. 1). During the first phase (some $30 \mathrm{~min}$ ), the change in growth rate was dependent on alcohol concentration above $0.53 \mathrm{M}$. The second phase was characterized by an increased generation time which remained constant as long as the culture was growing. As has been shown previously (Bohin et al., 1976), the generation time is doubled in the presence of 0.7 M-ethanol or $1.1 \mathrm{M}$-methanol under our growth conditions.

These effects on growth were completely and rapidly reversible (Fig. 2). When cells were transferred to a medium without alcohol, the initial growth rate was restored after a short lag the length of which depended on the concentration of alcohol in the previous medium. For cells cultivated in medium with $0.4 \mathrm{M}$-ethanol the lag was negligible; it lasted $8 \mathrm{~min}$ when the original ethanol concentration was $0.7 \mathrm{M}$. Reversibility (length of lag) was similar for cells grown either in ethanol or methanol at concentrations having the same effect on the generation time (Fig. 2).

These experiments were carried out with conditioned medium to avoid changes in the 


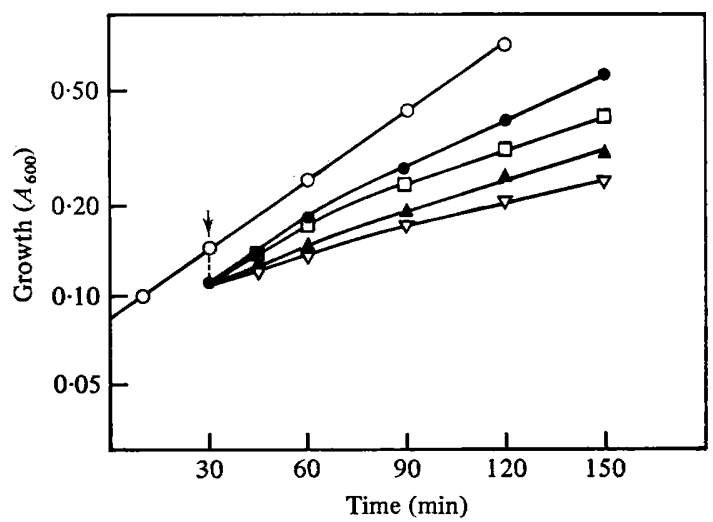

Fig. 1. Effect of ethanol at different concentrations on the growth of $B$. subtilis strain SMY. Cells were grown in conditioned nutrient broth at $37^{\circ} \mathrm{C}$; after $30 \mathrm{~min}$ incubation, ethanol was added (arrow). A maximum $A_{600}$ of $2 \cdot 0$ was reached in all cultures. Ethanol concentrations: $\mathrm{O}, 0$ (control); $0.53 \mathrm{M} ; \square, 0.70 \mathrm{M} ; \boldsymbol{\Delta}, 0.85 \mathrm{M} ; \nabla, 1.0 \mathrm{M}$.
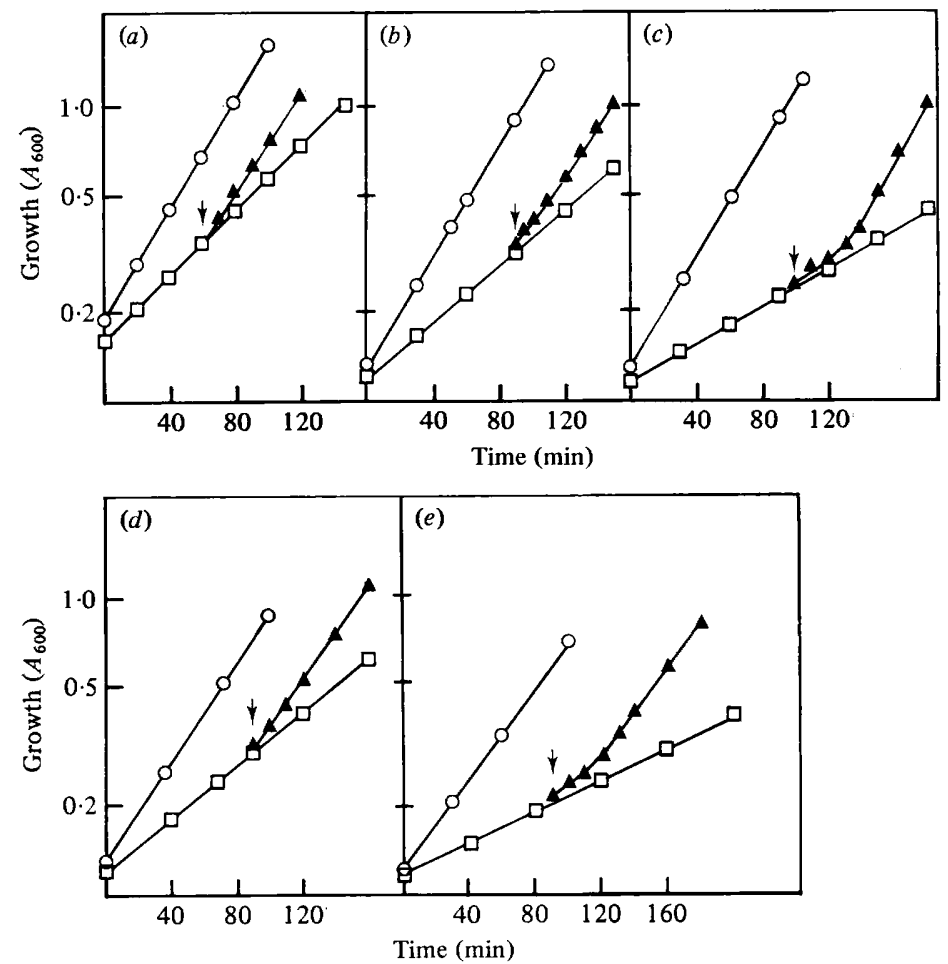

Fig. 2. Reversibility of the effect of alcohol on the growth of $B$. subtilis. Cells were incubated for five generations with different concentrations of alcohol: (a) 0.4 M-ethanol; (b) 0.7 M-ethanol; (c) $1.0 \mathrm{M}$-ethanol; (d) $1.0 \mathrm{M}$-methanol; (e) $1.5 \mathrm{M}$-methanol. At the time indicated (arrow), cells were harvested by filtration and re-incubated in the same volume of fresh medium equilibrated at $37^{\circ} \mathrm{C}$ : $\bigcirc$, control (no alcohol); $\square$, culture with alcohol; $\boldsymbol{\Lambda}$, re-incubation in fresh medium without alcohol. 


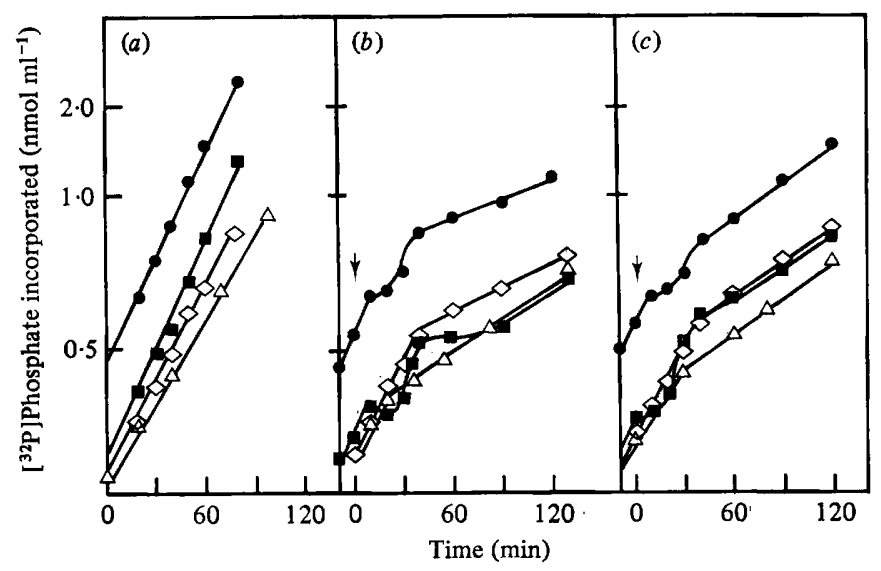

Fig. 3. Inhibition of $\left.{ }^{32} \mathrm{P}\right]$ phosphate incorporation by ethanol and methanol. Cells were incubated in conditioned nutrient broth with [ $\left.{ }^{32} \mathrm{P}\right]$ phosphate for two generations before alcohols were added (arrow): (a) control (no alcohol); (b) $0.7 \mathrm{M}$-ethanol; (c) $1.1 \mathrm{M}$-methanol. At intervals, the ${ }^{32} \mathrm{P}$ present in phospholipids was determined: $\bigcirc$, phospholipids; $\mathbf{\square}$, phosphatidylglycerol; $\diamond$, phosphatidylethanolamine; $\triangle$, lysophosphatidylglycerol.

growth rate induced by small amounts of rapidly metabolized substrates found in nutrient broth (Rigomier et al., 1974).

\section{Effects of ethanol and methanol on phospholipid metabolism}

Phospholipid synthesis, as measured by [ $\left.{ }^{32} \mathrm{P}\right]$ phosphate incorporation, was disturbed when alcohols were added to the growth medium. The effect was complex. Although the growth rate changed on addition of alcohol (first phase), there was no change in the rate of radioactivity incorporated in phosphatidylglycerol and in phosphatidylethanolamine for about $10 \mathrm{~min}$ and $30 \mathrm{~min}$, respectively (Fig. 3). After an abrupt and almost complete inhibition in phosphatidylglycerol labelling, there was a new surge of incorporation coincident with the second phase of growth and this continued at a rate commensurate with the new growth rate.

It took 90 min after adding $0.7 \mathrm{M}$-ethanol for [ $\left.{ }^{32} \mathrm{P}\right]$ phosphate incorporation in phospholipids to reach this last phase of adaptation. Addition of $1 \cdot 1 \mathrm{M}$-methanol to growing cells induced the same time course of changes as $0.7 \mathrm{M}$-ethanol; therefore phospholipid concentration was measured only after the rate of synthesis became directly proportional to the bacterial mass increase. Since the amount of lipid per cell was also affected by alcohols, values (Table 1) are given for the same increase in absorbance.

Although inhibition of lipid synthesis was not directly related to changes in the rate of growth after addition of alcohol, all the events observed are part of a physiological response. The fact that phosphatidylglycerol labelling was strongly inhibited before the final growth rate was observed supports the hypothesis that the new membrane structure and lipid composition were responsible for this last decrease.

The total amount of lipids and their relative concentrations were practically identical in cells grown in the presence of either methanol or ethanol (Table 1), but synthesis of each of the main phospholipids was inhibited differently at various alcohol concentrations. At $0.5 \mathrm{M}$, ethanol inhibited radioactivity incorporation in only phosphatidylglycerol and lysophosphatidylglycerol; at $0.7 \mathrm{M}$, inhibition of synthesis of these lipids reached $50 \%$ while phosphatidylethanolamine synthesis was reduced by $17 \%$ (Table 1 ).

Since phospholipids could have been solubilized by alcohols, thus explaining the smaller 


\section{Table 1. Inhibition of phospholipid labelling with $\left[{ }^{32} P\right]$ phosphate by ethanol and methanol}

Cells were incubated in conditioned nutrient broth with [ $\left.{ }^{32} \mathrm{P}\right]$ phosphate for at least three generations. Results are expressed as percentage inhibition, defined as $\left[\left(\mathrm{PL}_{\mathrm{t}}-\mathrm{PL}_{\mathrm{a}}\right) / \mathrm{PL}_{\mathrm{t}}\right] \times 100$, where $\mathrm{PL}_{\mathrm{a}}$ and $\mathrm{PL}_{\mathrm{t}}$ are the radioactivities incorporated in phospholipids during incubation with and without alcohols for the same change in $A_{600}$. Abbreviations: PL, phospholipid; PG, phosphatidylglycerol; PE, phosphatidylethanolamine; LysoPG, lysophosphatidylglycerol.

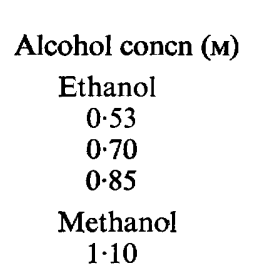

\begin{tabular}{cccc}
\multicolumn{4}{c}{ Percentage inhibition } \\
PL & PG & PE & LysoPG \\
31 & 41 & 0 & 45 \\
48 & 54 & 17 & 56 \\
67 & 77 & 46 & 58 \\
46 & 57 & 15 & 45
\end{tabular}

amounts found in the membrane, this possibility was checked. Phospholipids were never detected in the supernatant after centrifugation of cultures to which alcohol had been added.

Lipase activation by alcohols (Bernard et al., 1972) or higher osmolarity (Munro \& Bell, 1973) could also explain our results. We therefore measured the rate of phospholipid turnover in bacteria incubated with ethanol to see whether it was increased.

\section{Phosphatidylglycerol turnover in presence of alcohols}

In $B$. subtilis, phosphatidylethanolamine synthesis was stable both with and without added alcohol in the growth medium, while the renewal rate of phosphatidylglycerol was particularly fast under both conditions (Fig. $4 a, b$ ). In cells grown with [ $\left.{ }^{32} \mathrm{P}\right]$ phosphate, $50 \%$ of the label previously incorporated in phosphatidylglycerol was lost within 9 min after subsequent culture in non-radioactive medium (generation time was $35 \mathrm{~min}$ ). If alcohol was added at the time of transfer the turnover was only slightly increased; $50 \%$ of the label was lost in $8.5 \mathrm{~min}$.

A different result was obtained for phosphatidylglycerol synthesized in bacteria grown in the presence of alcohols. After transferring the cells to non-radioactive medium with ethanol, it took $28 \mathrm{~min}$ for a $50 \%$ decrease in radioactivity at a generation time of $72 \mathrm{~min}$ (Fig. $4 d$ ). Removing ethanol restored the initial growth rate, without any significant change in prelabelled phosphatidylglycerol turnover (Fig. $4 c$ ).

Thus, phosphatidylglycerol was more stable in cells grown in the presence of alcohols rather than less stable, as might have been expected. The smaller amount of phospholipids found in these cells could best be explained by an inhibition of lipid synthesis rather than by an activation of degrading enzymes.

Ethanol and methanol again had the same effects on phosphatidylglycerol turnover.

\section{Changes in fatty acid composition induced by ethanol or methanol}

Fatty acid composition has previously been shown to change during the cell cycle (Scandella \& Kornberg, 1969). Under our conditions, this was also true (Table 2). Therefore, the effects of alcohol on the fatty acid moiety were examined using cultures at one stage of exponential growth, i.e. at an $A_{600}$ of 0.50 .

With 0.7 M-ethanol added to the growth medium for many generations, the concentrations of 12-methyltetradecanoic acid (anteiso- $\mathrm{C}_{15}$ ) and 15-methylhexadecanoic acid (iso- $\mathrm{C}_{17}$ ) were reduced to $30 \%$ and $40 \%$ of their initial values, respectively (Table 3 ). This decrease was balanced by a relative increase in $\mathrm{C}_{16}$ and $\mathrm{C}_{18}$ linear fatty acids and in 16-methylheptadecanoic acid (iso- $\mathrm{C}_{18}$ ). 


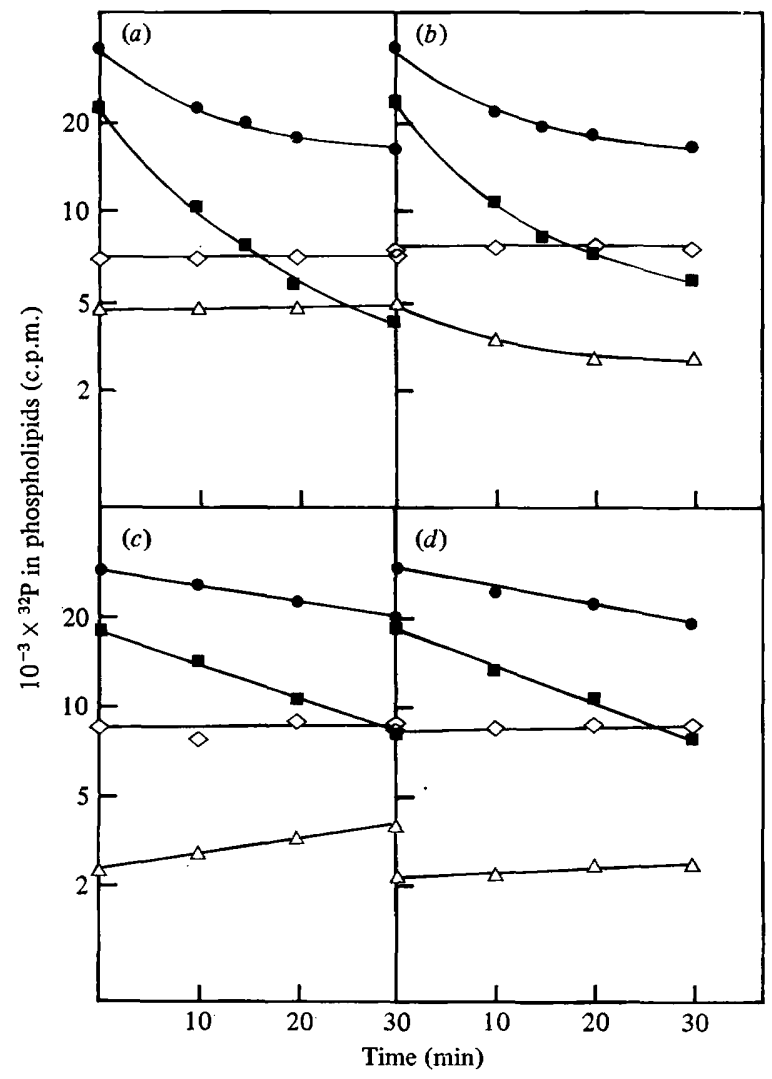

Fig. 4. Effect of ethanol on the turnover of phospholipids. Cells were incubated with [ $\left.{ }^{32} \mathrm{P}\right]$ phosphate in the absence $(a, b)$ or presence $(c, d)$ of $0.7 \mathrm{M}$-ethanol for at least three generations. Cells, in the mid-exponential phase of growth, were then harvested by filtration, washed with non-radioactive medium and re-incubated in the absence $(a, c)$ or presence $(b, d)$ of $0.7 \mathrm{M}$-ethanol. At intervals, the ${ }^{32} \mathrm{P}$ remaining in phospholipids was determined: 0 , phospholipids; $\boldsymbol{\square}$, phosphatidylglycerol; $\diamond$, phosphatidylethanolamine; $\triangle$, lysophosphatidylglycerol.

\section{Table 2. Changes in fatty acid composition in B. subtilis SMY during the growth cycle}

Cells were incubated in conditioned nutrient broth until the $A_{600}$ of the culture reached the value indicated; $t_{0}$ is the time at which growth stopped, and $t_{1}, t_{2}$ and $t_{4}$ indicate that incubation was continued for a further 1,2 and $4 \mathrm{~h}$, respectively. Lipids were extracted and fatty acids were transesterified as described in Methods. The amount of each fatty acid is expressed as a percentage of the total fatty acid composition. Fatty acid designations: i, iso-branched; a, anteiso-branched; n, normal (linear).

$\begin{array}{llll}0.35 & 1.5 & 1.9 & 3.4 \\ 0.50 & 1.3 & 1.6 & 3.6 \\ 1.5 t_{0} & 1.2 & 1.3 & 1.9 \\ t_{1} & - & 1.8 & 1.6 \\ t_{2} & - & 1.9 & 1.5 \\ t_{4} & - & 2.1 & 1.5\end{array}$

\begin{tabular}{|c|c|c|c|c|}
\hline \multicolumn{3}{|c|}{$\mathrm{C}_{14}$} & \multicolumn{2}{|c|}{$\mathrm{C}_{15}$} \\
\hline $\mathrm{i}$ & a & $\mathrm{n}$ & a & $\mathrm{n}$ \\
\hline 1.5 & 1.9 & $3 \cdot 4$ & $24 \cdot 3$ & $2 \cdot 9$ \\
\hline $1 \cdot 3$ & 1.6 & $3 \cdot 6$ & $35 \cdot 1$ & 3.0 \\
\hline $1 \cdot 2$ & 1.3 & 1.9 & 40.5 & 3.7 \\
\hline- & 1.8 & $1 \cdot 6$ & 48.5 & 1.0 \\
\hline- & 1.9 & 1.5 & 48.9 & - \\
\hline- & $2 \cdot 1$ & 1.5 & $56 \cdot 1$ & $2 \cdot 4$ \\
\hline
\end{tabular}

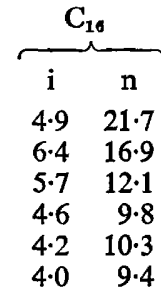

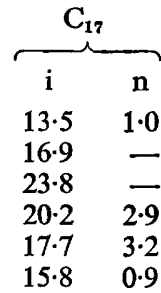

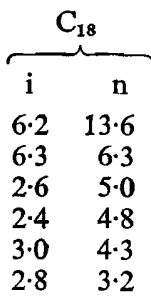


Table 3. Effect of methanol and ethanol on fatty acid composition in B. subtilis strain SMY

Cultures were incubated with or without alcohol at $37^{\circ} \mathrm{C}$ until the $A_{600}$ was $0 \cdot 5$. The amount of each fatty acid is expressed as a percentage of the total fatty acid composition. Fatty acid designations as in Table 2.

\begin{tabular}{|c|c|c|c|c|c|c|c|c|c|c|c|}
\hline \multirow[b]{2}{*}{ Alcohol } & \multicolumn{3}{|c|}{$\mathrm{C}_{14}$} & \multicolumn{2}{|c|}{$\mathrm{C}_{15}$} & \multicolumn{2}{|c|}{$\mathrm{C}_{16}$} & \multicolumn{2}{|c|}{$\mathrm{C}_{17}$} & $\mathrm{C}_{18}$ & Total \\
\hline & i & a & $\mathbf{n}$ & $\mathbf{a}$ & $\mathrm{n}$ & i & n & i & $\mathbf{n}$ & $\mathrm{n}$ & $\mathrm{a} / \mathrm{n} \mathrm{i} / \mathrm{n} \mathrm{a}$ \\
\hline None & $1 \cdot 3$ & 1.6 & $3 \cdot 6$ & $35 \cdot 1$ & $3 \cdot 0$ & $6 \cdot 4$ & $16 \cdot 9$ & 16.9 & $\rightarrow$ & $\begin{array}{ll}6 \cdot 3 & 6 \cdot 3\end{array}$ & $1 \cdot 2 \quad 1 \cdot 0$ \\
\hline Methanol (1.1 M) & $1 \cdot 1$ & $1 \cdot 1$ & $3 \cdot 0$ & 31.7 & $3 \cdot 0$ & $5 \cdot 1$ & $17 \cdot 8$ & $17 \cdot 8$ & $1 \cdot 4$ & $5 \cdot 7 \quad 7 \cdot 8$ & $1.0 \quad 0.9$ \\
\hline Ethanol $(0.7 \mathrm{M})$ & 0.6 & $1 \cdot 1$ & $5 \cdot 6$ & $10 \cdot 8$ & $1 \cdot 5$ & $5 \cdot 8$ & $27 \cdot 4$ & $6 \cdot 7$ & $1 \cdot 1$ & $16 \cdot 817 \cdot 7$ & 0.20 .6 \\
\hline
\end{tabular}

\section{Table 4. Effect of $0.7 \mathrm{M}$-ethanol on phospholipid labelling in different strains of $B$. subtilis}

Phospholipids were labelled with $\left[{ }^{32} \mathrm{P}\right]$ phosphate. Percentage inhibition and abbreviations are as defined in Table 1.

Percentage inhibition

\begin{tabular}{lcccc} 
Strain & PL & PG & PE & LysoPG \\
SMY & 48 & 55 & 17 & 56 \\
5NA R & 50 & 61 & 16 & 38 \\
5NA & 25 & 28 & $-5^{*}$ & 55 \\
3NA & 30 & 38 & $-20^{*}$ & 55 \\
\multicolumn{5}{l}{ * These values indicate increases of 5 and $20 \%}$.
\end{tabular}

In contrast to the effects on growth and phospholipid synthesis, $1 \cdot 1 \mathrm{M}$-methanol did not affect the fatty acid composition (Table 3). The response of $B$. subtilis SMY to methanol is thus different from its response to ethanol at the level of fatty acid incorporation into phospholipids. Ingram (1977a), working with Escherichia coli, did not observe any difference in fatty acid composition between cells grown in the presence of either methanol or ethanol. In $B$. cereus, ethanol induces an increase, instead of a decrease, in branched chain fatty acids (Kates et al., 1962). We therefore used, for comparison, asporogenous mutant strains of $B$. subtilis which had a phospholipid composition different from that of the wild-type (Rigomier \& Lubochinsky, 1974).

\section{Effects of alcohols on the growth of asporogenous mutants and on their phospholipid metabolism}

Alcohols had the same effect on growth of the asporogenous strains spo0 $\mathrm{A}$ 3NA and spo0A 5NA as on the wild-type strain SMY incubated under the same conditions (results not shown), but $\left[{ }^{32} \mathrm{P}\right]$ phosphate incorporation in phosphatidylethanolamine was enhanced. This stimulation reached $20 \%$ in strain 3NA (Table 4). The phosphatidylglycerol/phosphatidylethanolamine ratio, after alcohol was added to the growth medium, was similar to that of the wild-type under sporulating conditions. Yet these mutants did not sporulate - the phospholipid changes induced by the alcohols could not overcome the genetic alteration of membrane structure.

The effects of methanol and ethanol on the fatty acid composition of the asporogenous strains were similar to those observed in the wild-type (Table 5). Ethanol inhibition of the esterified anteiso- $\mathrm{C}_{15}$ was slightly less pronounced and the relative amount of this fatty acid was increased in cells grown with $1.1 \mathrm{M}$-methanol. This reproducible increase (from 33 to $38 \%$ ) was in the same direction as the change observed in the unsaturated fatty acid concentration in E. coli grown with ethanol (Ingram, 1977a). 


\section{Table 5. Effect of methanol and ethanol on fatty acid composition in $B$. subtilis strain spo0A 5NA}

Cultures were incubated with or without alcohol at $37^{\circ} \mathrm{C}$ until the $A_{600}$ was $0 \cdot 5$. The amount of each fatty acid is expressed as a percentage of the total fatty acid composition. Fatty acid designations as in Table 2.

Alcohol
None
Methanol $(1 \cdot 1 \mathrm{M})$
Ethanol $(0.7 \mathrm{M})$

\begin{tabular}{|c|c|c|c|c|}
\hline \multicolumn{3}{|c|}{$\mathrm{C}_{14}$} & \multicolumn{2}{|c|}{$\mathrm{C}_{15}$} \\
\hline i & $\mathbf{a}$ & $\mathbf{n}$ & $\mathbf{a}$ & $\mathbf{n}$ \\
\hline 1.5 & 1.4 & 3.8 & $33 \cdot 8$ & $2 \cdot 9$ \\
\hline 1.5 & 1.6 & $4 \cdot 4$ & $38 \cdot 1$ & 3.6 \\
\hline 0.6 & $1 \cdot 3$ & $5 \cdot 2$ & $12 \cdot 3$ & $3 \cdot 1$ \\
\hline
\end{tabular}

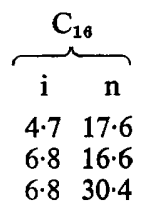

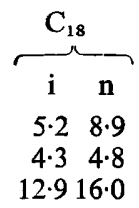

\section{DISCUSSION}

Addition of methanol or ethanol to a growing culture of $B$. subtilis can alter both phospholipid and fatty acid compositions. In B. subtilis, phospholipids account for 10 to $15 \%$ of the dry weight of the cytoplasmic membrane (Bishop et al., 1967), the only membrane structure in the vegetative cell. These phospholipids have a gel-to-liquid crystalline organization with a defined fluidity allowing physicochemical interactions with proteins and optimal expression of membrane-associated functions.

Adaptive responses occur in order to maintain the fundamental membrane properties. But, even after adaptation, $B$. subtilis growth was decreased by alcohols added to the medium. With 1.0 M-ethanol, growth remained exponential but the generation time was increased from 35 to $110 \mathrm{~min}$. The total cell mass (measured at $600 \mathrm{~nm}$ ) was, nevertheless, maximal at the end of the exponential phase. At concentrations lower than $0.82 \mathrm{M}$, the effects of ethanol on growth of $E$. coli K12 (Fried \& Novick, 1975) were similar to our observations on B. subtilis.

Another $E$. coli $\mathrm{K} 12$ strain showed a very different pattern of response to ethanol (Ingram, $1977 a$ ). At $30^{\circ} \mathrm{C}, 0.7 \mathrm{M}$-ethanol stopped growth for about $30 \mathrm{~min}$, then normal growth resumed. If alcohols simply modify the membrane viscosity by a change in fatty acid composition such behaviour might be expected. Under our conditions, we never observed normal growth of $B$. subtilis once alcohol had been added (in nutrient broth as well as in various mineral media) even after $16 \mathrm{~h}$ incubation. With $E$. coli, a difference in growth response could result from the use of a different medium since it is known that membrane phospholipid concentration, to which alcohol sensitivity could be related, is mediumdependent (Van Iterson \& Op den Kamp, 1969; Gill, 1976).

It was assumed that only the acylated fatty acids would be changed in response to factors affecting membrane viscosity. Membrane fluidization, however, important as it is, does not account for all the observed effects of alcohols on bacterial growth.

Once alcohol was removed from the medium, normal growth resumed, with or without a short delay. After incubation with alcohol at a low concentration, the growth rate was restored before any change in lipids could be measured (results not shown). Thus, growth was not reduced as a consequence of changes in the lipid content of the membrane. It must therefore be inferred that alcohols act also on easily reversible molecular interactions within the membrane, like those involving molecules which are more or less hydrated. These changes in physical properties can rapidly be reversed (Jain \& Wu, 1977).

After incubation with ethanol or methanol at concentrations above $0.7 \mathrm{M}$ and $1 \cdot 1 \mathrm{M}$, respectively, a lag was observed before normal growth resumed (Fig. 2). In these bacteria, phospholipid content was reduced to less than $50 \%$ of that found in bacteria grown in alcohol-free medium. A significant synthesis of phospholipids, particularly phosphatidylglycerol, must take place to allow the normal growth rate to be achieved (results not shown). 
This is in accordance with the effects of cessation and re-initiation of phospholipid synthesis on macromolecular synthesis in plsB mutants of $E$. coli (McIntyre et al., 1977).

Methanol and ethanol have different lipid/water partition coefficients. Though distribution coefficients of short-chain alcohols for a two-phase system, water/tetradecane, are very small (Hui \& Barton, 1973), their partition between water and biological membranes cannot be directly compared. The mobility of the 5-nitroxide derivative of stearic acid, used as a probe in mitochondrial membrane studies, was affected by both methanol and ethanol, but three times more methanol was required for the same effect (Lenaz et al., 1976).

An accumulation of alcohol radicals within the polar part of the membrane could be responsible for a significant decrease in synthesis of phosphatidylglycerol, a molecule having free hydroxylated groups. With increasing concentrations of methanol, synthesis of phosphatidylethanolamine was also inhibited. The observed change in the phosphatidylglycerol/ phosphatidylethanolamine ratio is in agreement with this hypothesis.

Ethanol, a short-chain alcohol, acts like methanol but, being slightly more soluble in the hydrophobic zone, decreases membrane viscosity. Therefore, when ethanol was added to the culture, it promoted, as a second response, an increase in linear fatty acid incorporation correlated with a decrease in branched-chain fatty acid incorporation in phospholipids. A similar effect, observed after a shift up in temperature, has been ascribed to a reaction against membrane fluidization (Sinensky, 1971).

Short-chain alcohols $\left(\mathrm{C}_{1}\right.$ to $\left.\mathrm{C}_{4}\right)$ added to $E$. coli cultures promote an increase in the unsaturated vaccenic acid content (Ingram, 1977a). With $B$. subtilis, ethanol does not induce a reaction against fluidization; instead it acts as a fluidizing agent. The reason for such a difference between the two bacteria is not, as yet, understood especially since in $E$. coli short-chain alcohols promote only transient changes in the phospholipids ratio (Ingram, 1977b).

The complex structure of $E$. coli membranes prevents a simple and direct analysis. A general explanation should take into account the different solubilities of methanol and ethanol in the hydrophobic zones and their concentrations within different parts of the envelope. The various physiological effects of alcohols might be more easily interpreted working with $B$. subtilis, a bacterium with a single membrane.

Regulation of the fatty acid synthetase system in $B$. subtilis is still not well understood. Ethanol and methanol, at concentrations having the same effect on growth, inhibited fatty acid synthesis to the same extent as measured by $\left[{ }^{14} \mathrm{C}\right]$ acetate incorporation (Buttke \& Ingram, 1978) - a response similar to its temperature dependence (Sinensky, 1971). But fatty acid and phospholipid synthesis are tightly co-regulated; alcohols could act at the level of regulation mechanisms, for example at the level of control processes exerted by nucleotides (ppGpp) (Merlie \& Pizer, 1973).

A change in affinity or activity of the enzyme required for the synthesis of branched-chain precursors or a change in acyltransferase specificity could explain the inhibitory effect of ethanol and anteiso- $\mathbf{C}_{\mathbf{1 5}}$ incorporation in phospholipids. Such a change in specificity of glycerol-3-phosphate acyltransferase accounts for the physiological response of growing $E$. coli to an upward shift in temperature (Sinensky, 1971).

Since short-chain alcohols such as ethanol and methanol modify the hydration state of polar head-groups, they could also change what is described as interfacial regulation (Sandermann, 1978). Analysis of chemical perturbations induced by these alcohols may lead to a better understanding of molecular interactions in biological membranes.

This work was supported by the Centre National de la Recherche Scientifique (grant ATP no. A13065 00) and the Délégation Générale à la recherche scientifique. 


\section{REFERENCES}

Bernard, M. C., Brisou, J., Denis, F. \& Rosenberg, A. J. (1972). Présence d'une phospholipase A chez Escherichia coli O118.1 - mise en évidence de deux états de l'enzyme et propriétés. Biochimie 54, 261-270.

Bishop, D. G., Rutberg, L. \& Samuelsson, B. (1967). The chemical composition of the cytoplasmic membrane of Bacillus subtilis. European Journal of Biochemistry 2, 448-453.

BLIGH, E. G. \& DYER, W. J. (1959). A rapid method of total lipid extraction and purification. Canadian Journal of Biochemistry and Physiology 37, 911917.

BohiN, J. B., Rigomier, D. \& SchaefFer, P. (1976). Ethanol sensitivity of sporulation in Bacillus subtilis: a new tool for the analysis of the sporulation process. Journal of Bacteriology 127, 934 940.

ButTKe, T. M. \& INGRAM, L. O. (1978). Mechanism of ethanol induced changes in lipid composition of Escherichia coli: inhibition of saturated fatty acid synthesis in vivo. Biochemistry 17, 637-644.

FRIED, V. A. \& NoviCK, A. (1975). Organic solvents as probes for the structure and function of bacterial membrane: effects of ethanol on the wild type and an ethanol-resistant mutant of Escherichia coli K12. Journal of Bacteriology 114, 239248.

Fujir, D. K. \& Fulco, A. J. (1977). Biosynthesis of unsaturated fatty acids. Hyperinduction and modulation of desaturase synthesis. Journal of Biological Chemistry 252, 3660-3670.

GiLl, C. O. (1976). Effects of growth temperature on the lipids of Pseudomonas fluorescens. Journal of General Microbiology 89, 293-298.

HaRold, F. M. (1970). Antimicrobial agents and membrane function. Advances in Microbial Physiology 4, 45-104.

Hui, F. K. \& BARTON, P. G. (1973). Mesomorphic behaviour of some phospholipids with aliphatic alcohols and other nonionic substances. Biochimica et biophysica acta 296, 510-517.

INGRAM, L. O. (1977a). Preferential inhibition of phosphatidylethanolamine synthesis in Escherichia coli by alcohols. Canadian Journal of Microbiology 23, 779-789.

INGRAM, L. O. (1977b). Changes in lipid composition of Escherichia coli resulting from growth with organic solvents and with food additives. Applied and Environmental Microbiology 33, 1233-1236.

VAN ITERSON, W. \& OP DEN KAMP, J. A. F. (1969). Bacterial shaped gymnoplasts (protoplasts) of Bacillus subtilis. Journal of Bacteriology 99, 304315.

JAIN, M. K. \& WU, N. M. (1977). Effect of small molecules on the dipalmitoyl lecithin liposomal bilayers: phase transition in lipid bilayer. Journal of Membrane Biology 34, 157-201.

Kates, M., Kushner, D. J. \& James, A. T. (1962). The lipid composition of Bacillus cereus as influenced by the presence of alcohols in the culture medium. Canadian Journal of Biochemistry and Physiology 40, 83-93.
Lenaz, G., Bertoli, E., Curatola, G., Mazzanti, L. \& BIGI, A. (1976). Lipid protein interactions in mitochondria: spin and fluorescence probe studies on the effects of n-alkanols on phospholipid vesicles and on mitochondrial membranes. Archives of Biochemistry and Biophysics 172, 278298.

MarR, A. G. \& IngrahaM, J. L. (1962). Effect of temperature on the composition of fatty acids in Escherichia coli. Journal of Bacteriology 84, 12611267.

McIntyre, T. M., Chamberlain, B. K., Webster R. E. \& BELL, R. M. (1977). Mutants of Escherichia coli defective in membrane phospholipid synthesis. Effects of cessation and reinitiation of phospholipid synthesis on macromolecular synthesis and phospholipid turnover. Journal of Biological Chemistry 252, 4487-4493.

Merlie, J. P. \& Pizer, L. T. (1973). Regulation of phospholipid synthesis in Escherichia coli by guanosine tetraphosphate. Journal of Bacteriology 116, 355-366.

Michaelson, D. M., HoRwitz, A. F. \& Klein, M. P. (1974). Head group modulation of membrane fluidity in sonicated phospholipid dispersions. Biochemistry 13, 2605-2611.

Michel, J. F., Cami, B. \& Schaeffer, P. (1968). Sélection de mutants de Bacillus subtilis bloqués au début de la sporulation. Annales de l'Institut Pasteur 114, 11-27.

Munro, G. F. \& Bell, C. A. (1973). Effects of external osmolarity on phospholipid metabolism in E. coli B. Journal of Bacteriology 116, 257-262.

OKuYama, H., Yamada, K., KameYama, Y., Ikezawa, H., Akamatsu, Y. \& NoJima, S. (1977). Regulation of membiane lipid synthesis in Escherichia coli after shifts in temperature. Biochemistry 16, 2668-2673.

Patterson, S. J., Butler, K. W., Huang, P., Labelle, J., Smith, I. C. P. \& Schneider, H. (1972). The effects of alcohols on lipid bilayers: a spin label study. Biochimica et biophysica acta 246, 1062-1072.

Rigomier, D. \& Lubochinsky, B. (1974). Métabolisme des phospholipides chez des mutants asporogènes de Bacillus stibtilis au cours de la croissance exponentielle. Annales de Microbiologie 125B, 295-303.

Rigomier, D., Lubochinsky, B. \& Schaeffer, P. (1974). Composition en phospholipides de mutants asporogènes de Bacillus subtilis. Comptes rendus hebdomadaires des séances de l'Académie des sciences 278, 2059-2062.

Saito, Y. \& McElhaney, R. N. (1977). Membrane lipid biosynthesis in Acholeplasma laidlawii B: incorporation of exogenous fatty acids into membrane glyco- and phospholipids by growing cells. Journal of Bacteriology 132, 485-496.

SANDERMANN, H. (1978). Regulation of membrane enzymes by lipids. Biochimica et biophysica acta 515, 209-237.

SCANDElla, C. J. \& KornberG, A. (1969). Biochemical studies of bacterial sporulation and 
germination. XV. Fatty acids in growth, sporulation and germination of Bacillus megaterium. Journal of Bacteriology 98, 82-86.

SinenSKY, M. (1971). Temperature control of phospholipid biosynthesis in Escherichia coli. Journal of Bacteriology 106, 449-455.

SINENSKY, M. (1974). Homeoviscous adaption - an homeostatic process that regulates the viscosity of the membrane lipids in Escherichia coli. Proceedings of the National Academy of Sciences of the United States of America 71, 522-525.

Vaughan, D. J. \& KeOUgh, K. M. (1974). Changes in phase transitions of phosphatidylethanolamine - and phosphatidylcholine - water dispersions induced by small modifications in the headgroup and backbone regions. FEBS Letters 47, 158-161. 